\title{
Effects of exclosure on aboveground biomass, vegetation constitution, and midday gross primary productivity in semi-arid Mongolian steppe
}

\author{
Tadaaki URANO*i, Mitsuru HIROTA*, Byambakhuu ISHGALDAN*, \\ Sheng-Gong LI**, Jun ASANUMA*, Shigeru MARIKO***, \\ Michiaki SUGITA*, and Takehisa OIKAWA*

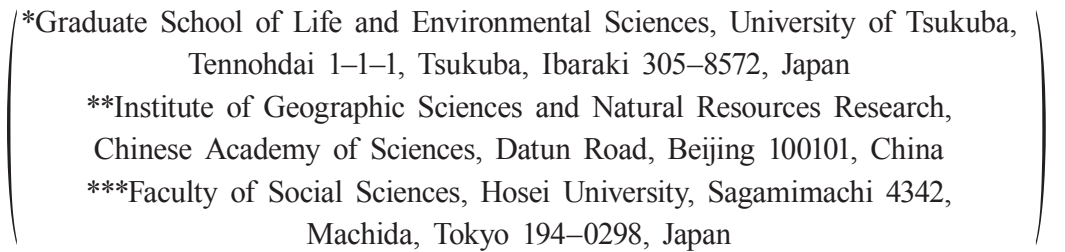

\begin{abstract}
We examined the effects of grazing on aboveground biomass (AGB), vegetation constitution, and gross primary productivity (GPP) at midday in midsummer on a Mongolian steppe with mixed vegetation consisting of $\mathrm{C}_{3}$ and $\mathrm{C}_{4}$ plants. A grazed area (GA) and a nongrazed area (NGA) created by an exclosure were established in 2002 on land with a history of conventional grazing management. AGB of the mixed $\mathrm{C}_{3}-\mathrm{C}_{4}$ vegetation was determined in the GA and NGA from 2003 to 2006. Nongrazing resulted in increased $\mathrm{AGB}$ and a decreased ratio of $\mathrm{C}_{4}$ AGB to total AGB. In 2003 and 2006 a dynamic closed-chamber method was used to measure midday GPP; there was no significant difference between the GA and NGA in either year. Partitioning analysis of midday GPP to $\mathrm{C}_{3}$ and $\mathrm{C}_{4}$ photosynthesis indicated that exclosure exerted little influence on the midday GPP in midsummer, because the enhancement of GPP by increased AGB was offset by the reduced AGB of $\mathrm{C}_{4}$ plants.
\end{abstract}

Key words: Biomass; $\mathrm{C}_{3} / \mathrm{C}_{4}$ plants; Community; GPP; Grazing; Mongolia.

\section{Introduction}

Steppe is the second largest biome in Asia and has a great influence on the Asian and/or global carbon cycle. In Mongolia, steppe occupies $75 \%$ of the total land area and has been grazed by domestic livestock for several thousand years (Fernandez-Gimenez and Allen-Diaz, 1999; Zhang et al., 2007). Recent changes in the social structure of Mongolia have accelerated overgrazing and

Received; October 21, 2009.

Accepted; June 24, 2010.

†Correspondence Author: s0630469@ipe.tsukuba.ac.jp (T. Urano)

Graduate School of Life and Environmental Sciences, University of Tsukuba, Tennohdai 1-1-1, Tsukuba, Ibaraki 305-8572, Japan. have thus contributed to a decline in productivity of the steppe (Jigmed, 2006). Overgrazing of the world's grasslands by domestic livestock has been implicated in the reduction in global carbon uptake (LeCain et al., 2002). Therefore, the impact of grazing on the carbon dynamics of the vast Mongolian grassland ecosystem needs to be better understood.

Exclosure proved an effective technique for restoring the semi-arid steppe vegetation of Inner Mongolia, where overgrazing has caused a serious decline in the vegetation and the conversion of semi-arid grassland to desert (Su et al., 2005). However, although the aboveground biomass (AGB) inside an exclosure is enhanced, the protected vegetation has lower species diversity than the grazed vegetation because of selective feeding and trampling of grasses outside the exclosure (Tessier et al., 2003; Chen et al., 2005; Pei et al., 
2008).

In semi-arid grasslands, a hot and dry climate in midsummer favors $\mathrm{C}_{4}$ plants over $\mathrm{C}_{3}$ plants, as seen in Inner Mongolia (Liang et al., 2002), because $\mathrm{C}_{4}$ photosynthesis is adapted to high temperatures and shows a high water-use efficiency (Larcher, 2003). In warm-temperate mixed $\mathrm{C}_{3}-\mathrm{C}_{4}$ vegetation, a welldeveloped canopy dominated by $\mathrm{C}_{4}$ plants achieved higher carbon gains (Li et al., 2003). But the impact of grazing on AGB was greater for $\mathrm{C}_{4}$ plants in a Mongolian grassland (Nachinshonhor et al., 2000). Therefore, any decrease in the AGB ratio of $\mathrm{C}_{4}$ plants to $\mathrm{C}_{3}$ plants caused by grazing could reduce gross primary productivity (GPP). However, there has been no comparison of GPP between grazed and nongrazed areas of Mongolian semi-arid grasslands in terms of the impact of grazing on the $\mathrm{C}_{4}$ to $\mathrm{C}_{3}$ biomass ratio.

Our objectives was to investigate the effects of summer grazing on the AGB and midday GPP of a Mongolian semi-arid grassland dominated by mixed $\mathrm{C}_{3}-\mathrm{C}_{4}$ herbs. An exclosure was established in 2002 to exclude grazing livestock, and AGB was then determined over the 4 years between 2003 and 2006. Midday GPP was measured in mixed $\mathrm{C}_{3}-\mathrm{C}_{4}$ plots and in exclusive $\mathrm{C}_{3}$ or $\mathrm{C}_{4}$ plots in the first year after exclosure establishment, but only in the mixed plot in the fourth year. The results were related to photosynthetic photon flux density (PPFD), air temperature ( $T a$ ), and soil water content (SWC).

\section{Materials and methods}

\subsection{Study site}

The study was conducted in Kherlen Bayan Ulaan (KBU; $47^{\circ} 12^{\prime} \mathrm{N}, 108^{\circ} 44^{\prime} \mathrm{E}$, elevation $1235 \mathrm{~m}$ ), in Hentiy Prefecture, $250 \mathrm{~km}$ southeast of Ulaanbaatar, Mongolia. $\mathrm{KBU}$ is located on the central typical Mongolian steppe. The climate of the KBU steppe is characterized by a hot rainy summer and a cold dry winter. Annual precipitation during the 5 years of the study varied from $166 \mathrm{~mm}$ (2005) to $260 \mathrm{~mm}$ (2003). Volumetric soil water content at $10 \mathrm{~cm}$ depth varies annually from about $2 \%$ to $25 \%$ and is not less than $7 \%$ during the growing season (Li et al., 2005).

The vegetation of the KBU steppe consists of short $\mathrm{C}_{3}-\mathrm{C}_{4}$ mixed grasses and forbs: $\mathrm{C}_{3}$ grasses and sedges (Stipa krylovii Roshev., Carex spp.), $\mathrm{C}_{3}$ forbs (Artemisia frigida W., Artemisia adamsii B., Potentilla bifurca L.), and $\mathrm{C}_{4}$ plants (Cleistogenes squarrosa (T.) Keng, Salsola collina P., Kochia scoparia (L.)
Schrad (Kawada et al., 2007). $\mathrm{C}_{4}$ species constitute $10 \%$ of all plant species in KBU and 3\% of all plant species in Mongolia (Pyankov et al., 2000; Kawada et al., 2007). Domestic animals graze the vegetation year-round; nomads pasture their animals on the dead grasses in winter. Grazing pressure was 0.6 to 0.7 sheep-equivalent units $\mathrm{ha}^{-1}$ between 2001 and 2004 (Onda et al., 2007). To exclude grazing impacts, in August 2002 we constructed an exclosure (3.4 ha; 170 $\mathrm{m} \times 200 \mathrm{~m}$ ) as a nongrazed area (NGA). A grazed area (GA) of the same size was located at its north side.

\subsection{Environmental measurements}

To obtain local meteorological data, we constructed two meteorological towers, one within the exclosure and one $450 \mathrm{~m}$ northeast. Micrometeorological measurements were made by sensors and dataloggers mounted on each tower. A temperature and relative humidity sensor (HMP45D; Vaisala Inc., Helsinki, Finland) was mounted $2.5 \mathrm{~m}$ above the ground. Half-hourly mean data were recorded on a CR23X datalogger (Campbell Scientific, Logan, UT, USA).

We measured soil water content (SWC) at a depth of $5 \mathrm{~cm}$ with a time-domain reflectometry probe (CS616, Campbell Scientific). Precipitation was measured in a tipping-bucket rain gauge (CYG-52202; RM Young Company, Traverse City, MI, USA). Half-hourly mean data were recorded on a CR10X datalogger (Campbell Scientific).

\subsection{Vegetation measurements}

Just before the exclosure was established, the vegetation structure in the area was investigated by harvesting the aboveground parts of plants in 36 randomly placed $1-\mathrm{m}^{2}$ quadrats in August 2002. There were no significant differences in species composition, vegetation height, coverage, or AGB among the quadrats. We therefore assumed that there was no difference in vegetation composition and biomass between the GA and NGA before the exclosure was set. For more information on the vegetation structure, see Kawada et al. (2007).

To examine the effect of grazing on AGB, we partitioned the GA and the NGA into four equal compartments each and placed a $20-\mathrm{m} \times 20$-m quadrat at the center of each. Three small $\left(0.25-\mathrm{m}^{2}\right)$ quadrats were randomly placed in each large quadrat, giving a total of 12 small quadrats in the GA and 12 in the NGA. The aboveground plant parts in the small quadrats were clipped at ground level in July or August 2003, 2004, and 2006. In all years, clipped samples were divided 
into $\mathrm{C}_{3}$ and $\mathrm{C}_{4}$ plants, dried in a ventilated oven at $60^{\circ} \mathrm{C}$ for $72 \mathrm{~h}$, and then weighed.

The stocking rate was calculated for every measurement season by using a stocking rate calculator (Meat \& Livestock Australia, North Sydney, NSW, Australia). The parameters set were paddock size $=1$; pasture available at start of grazing $=0$; pasture to be left at end of grazing =AGB in GA; and pasture growth rate= AGB in NGA per number of days from day 1 of plant growth, as advised by local grazing managers.

We used KaleidaGraph v. 3.6.4 (Synergy Software, Reading, PA, USA) to compare total AGB and the ratio of $\mathrm{C}_{4} \mathrm{AGB}$ to total $\mathrm{AGB}$ between the GA and NGA by $t$-test in 2003, 2004, and 2006. We used SPSS v. 13 (SPSS Inc., Chicago, IL, USA) to evaluate the effects of exclosure, photosynthetic types, and temporal variations on $\mathrm{AGB}$ by stepwise multiple regression analysis, here we used dummy numbers ( 0 or 1$)$ for binomial parameters.

\section{4 $\mathrm{CO}_{2}$ flux measurements}

GPP was calculated from data on net $\mathrm{CO}_{2}$ exchange measured under light and dark conditions ( $F_{\text {light }}$ and $F_{\text {dark}}$, respectively) by using a dynamic closed-chamber method. Diurnal variations were measured on 11 July and 22 August 2003. In July and August 2003 and in July 2006, midday GPP was measured between 10:30 and 13:00 local time, because diurnal measurements showed that the peak GPP occurred during this time on a clear day when the PPFD was higher than 1000 $\mu \mathrm{mol} \mathrm{m} \mathrm{m}^{-2} \mathrm{~s}^{-1}$ (Urano, 2006). Two datasets of midday GPP measurements were prepared, one for determining grazing impact (comparison between mixed $\mathrm{C}_{3}-\mathrm{C}_{4}$ vegetation in the GA and NGA) and the other for determining the difference in potential GPP on a biomass basis among the three vegetation types (comparison among $\mathrm{C}_{3}$ vegetation, $\mathrm{C}_{4}$ vegetation, and mixed $\mathrm{C}_{3}-\mathrm{C}_{4}$ vegetation). Separate $C_{3}$ and $C_{4}$ vegetation mini-plots were artificially created by removing the aboveground parts of $\mathrm{C}_{4}$ plants and $\mathrm{C}_{3}$ plants, respectively, under the chambers more than 1 day before every measurement. Midday GPP measurements for grazing impact were made in five mini-plots (the same number of chambers) in the GA and NGA in August 2003, and in 10 mini-plots in the GA and NGA in July 2006. Potential midday GPP, expressed on a biomass basis, was measured in four $\mathrm{C}_{3}$ and four $\mathrm{C}_{4}$ mini-plots and in 10 mixed $\mathrm{C}_{3}-\mathrm{C}_{4}$ mini-plots in 2003 , but one of the four $\mathrm{C}_{4}$ mini-plots was not used because the chamber was destroyed. The chamber mini-plots were placed at random $2 \mathrm{~m}$ apart from each other.

The dynamic closed chamber was divided into two parts: an acrylic transparent top and a dark polyvinyl chloride collar, each $10 \mathrm{~cm}$ high and $21 \mathrm{~cm}$ in diameter. A photosynthetic photon flux meter (IKS-25; Koito Industry, Japan) was mounted on the chamber top, and a thermocouple and air-mixing fan were installed inside. Before PPFD measurements, the collar was installed at a soil depth of $6 \mathrm{~cm}$. First, to measure $F_{\text {light, }}$, the transparent chamber top was placed on the collar. Then air in the closed chamber was sent to a $\mathrm{CO}_{2}$ analyzer (Li-820; LI-COR, Inc., Lincoln, NE, USA) and back to the chamber by an air pump with a flowmeter (MP- $\sum 300$; Sibata, Japan) at a flow rate of 0.95-0.98 $\mathrm{L} \mathrm{min}^{-1}$. The gas analyzer measured $\mathrm{CO}_{2}$ concentration within an error range of $1 \mathrm{ppm}$. Data on $\mathrm{CO}_{2}$ concentration, PPFD, and temperature in the transparent chamber were logged by a datalogger (Thermic 2300A; Eto Denki Ltd., Japan) at intervals of $5 \mathrm{~s}$ over a period of $180 \mathrm{~s}$. The chamber top was then removed to ventilate the closed chamber with fresh air, the chamber top was replaced on the collar, and the closed chamber was covered by an aluminum shading box (inside PPFD $<1 \mu \mathrm{mol} \mathrm{m}{ }^{-2} \mathrm{~s}^{-1}$ ). The $\mathrm{CO}_{2}$ concentration, PPFD, and temperature in the dark chamber were then recorded to obtain data for the calculation of $F_{\text {dark. }} F_{\text {light }}$ and $F_{\text {dark }}$ were calculated by linear regression between the $\mathrm{CO}_{2}$ concentration inside the chamber and the sampling time.

The midday GPP is the sum of the measured $F_{\text {light }}$ and $F_{\text {dark }}$ :

$$
\text { Midday GPP }=F_{\text {light }}+F_{\text {dark }}
$$

The contributions of $\mathrm{C}_{3}$ and $\mathrm{C}_{4}$ photosynthesis to midday GPP measured in the mixed vegetation were estimated by assuming that the measured GPP was equal to the sum of the estimated GPPs of $\mathrm{C}_{3}$ plants and $\mathrm{C}_{4}$ plants.

After recording of PPFD measurements, live plants inside the chamber were clipped at ground level and dried at $60^{\circ} \mathrm{C}$ for $72 \mathrm{~h}$, then weighed to give $\mathrm{AGB}_{\mathrm{c}}$. By using $\mathrm{AGB}_{\mathrm{c}}$, the midday GPP on a chamber-area basis was transformed into the GPP on a dry-weight basis. The midday GPP on a land-area basis was calculated by multiplying the dry-weight-based GPP and AGB measured in the quadrats.

We used KaleidaGraph v. 3.6 for Tukey's HSD test for comparison of diurnal variations in GPP and AGB between the GA and NGA in 2003, among $\mathrm{C}_{3}, \mathrm{C}_{4}$, and 
mixed $\mathrm{C}_{3}-\mathrm{C}_{4}$ vegetations, and among estimated GPPs of $\mathrm{C}_{3}, \mathrm{C}_{4}$, and mixed $\mathrm{C}_{3}-\mathrm{C}_{4}$ vegetations between the GA and NGA. The relationships between measured GPP and calculated GPP was examined by fitting to a linear regression model and between AGB and GPP was examined by fitting to the Michaelis-Menten kinetics as GPP-LAI non-linear regression model (Byrne et al., 2005) using estimated LAI (LAI $=0.071 * A G B, r=0.79$, $t$-value $=16.1, p<0.001$; see Sugita et al., 2007):

$$
\mathrm{GPP}=\frac{a * \mathrm{LAI}}{(b+\mathrm{LAI})}
$$

where $a$ is the maximum GPP and $b$ is the slope.

We used SPSS 13 for a stepwise multiple regression to evaluate the effects of exclosure, photosynthetic types, and temporal variations on midday GPP, here we used dummy numbers ( 0 or 1$)$ for binomial parameters. We used $\mathrm{R}$ for analyze the parameters of the GPP-LAI regression model. $\mathrm{R}$ is a language and environment for statistical computing and graphics similar to $\mathrm{S}$ http://cran.r-project.org/.

\section{Results}

\subsection{Aboveground biomass}

The total AGB of mixed vegetation in the GA decreased each year, from 85 g D.W. $\mathrm{m}^{-2}$ in 2003 to 69 g D.W. $\mathrm{m}^{-2}$ (2004) and 56 g D.W. $\mathrm{m}^{-2}$ (2006) (refer to Fig. 1). The total AGB of mixed vegetation in the NGA varied between years, from 98 g D.W. $\mathrm{m}^{-2}$ in 2003 to 112 g D.W. $\mathrm{m}^{-2}$ (2004) and 80 g D.W. $\mathrm{m}^{-2}$ (2006). The estimated stocking rates of the GA in 2003, 2004, and 2006 were $0.7,0.7$, and 0.9 sheep equivalent units ha ${ }^{-1}$, respectively. With the exception of the first year, which marked the start of the exclusion experiment, the total AGB in the GA was significantly lower ( $t$-test; $P<$ 0.05) than that in the NGA (see Fig. 1). The ratio of $\mathrm{C}_{4}$ AGB to total AGB in the GA showed no change over the study period. In the NGA, the ratio of $\mathrm{C}_{4}$ AGB to total AGB was $15 \%$ in 2003 (identical to that in the GA) but decreased to $10 \%$ by 2004 and to $5 \%$ in 2006. The ratio was significantly higher in the GA than in the NGA in 2006 (refer to Fig. 1).

There was no significant difference in either total $\mathrm{AGB}$ or $\mathrm{C}_{4} \mathrm{AGB}$ between treatments or between months (see Table 1), indicating that GPP measurements taken in both July and August 2003 were not influenced by the change in $\mathrm{AGB}$ and $\mathrm{C}_{3}-\mathrm{C}_{4}$ species composition over this 2-month period (refer to Figs. $2,3)$. The stepwise multiple analysis showed that

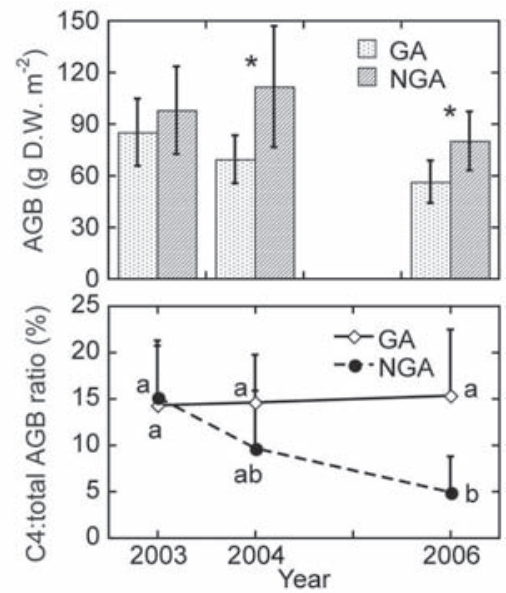

Fig. 1. Temporal variations in total aboveground biomass (AGB) and the ratio of $\mathrm{C}_{4} \mathrm{AGB}$ to total AGB in the GA and NGA from 2003 to 2006. Bars represent standard deviation $(n=12)$. Asterisks and different letters show significant differences by $t$-test $(P<0.05)$.

Table 1. Comparison of aboveground biomass (AGB) in mid-July and mid-August 2003.

\begin{tabular}{|c|c|c|c|}
\hline \multirow{2}{*}{\multicolumn{4}{|c|}{ AGB (g D.W. $\mathrm{m}^{-2}$ ) }} \\
\hline & 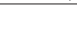 & Mid-July & Mid-August \\
\hline \multirow{2}{*}{ Total AGB } & GA & $66.2 \pm 10.4(\mathrm{a})$ & $85.1 \pm 18.7(\mathrm{ab})$ \\
\hline & NGA & $88.2 \pm 23.4(\mathrm{ab})$ & $97.9 \pm 24.4(b)$ \\
\hline \multirow{2}{*}{$\mathrm{C}_{4} \mathrm{AGB}$} & GA & $13.1 \pm 8.7$ (a) & $12.7 \pm 11.3(\mathrm{a})$ \\
\hline & NGA & $9.5 \pm 5.5$ (a) & $14.8 \pm 10.1(\mathrm{a})$ \\
\hline
\end{tabular}

Results are means \pm SD of 12 plots.

Same letters in parentheses indicate no significant difference at $p=0.05$.

significant variables for predicting AGB variations were exclosure, photosynthesis type, and year, but not month (see Table 3).

\subsection{Diurnal variation in $\mathrm{C}_{3}$ and $\mathrm{C}_{4}$ GPP}

We examined the diurnal variation in GPP of $\mathrm{C}_{3}$ and $\mathrm{C}_{4}$ vegetation and in PPFD and temperature on 11 July and 22 August 2003 (see Fig. 2). PPFD peaked between 12:00 and 14:00 local time on both dates. On 11 July and 22 August the minimum and maximum diurnal air temperatures were 11.3 and $26.6^{\circ} \mathrm{C}$ and 7.9 and $23.2^{\circ} \mathrm{C}$, respectively. Air temperature was lowest between 05:00 and 07:00 and highest between 13:00 and 16:00 local time each day. GPP of both $\mathrm{C}_{3}$ and $\mathrm{C}_{4}$ vegetation was highly dependent on PPFD in both July and August, and peaked when the PPFD exceeded $1000 \mu \mathrm{mol} \mathrm{m}^{-2} \mathrm{~s}^{-1}$. 


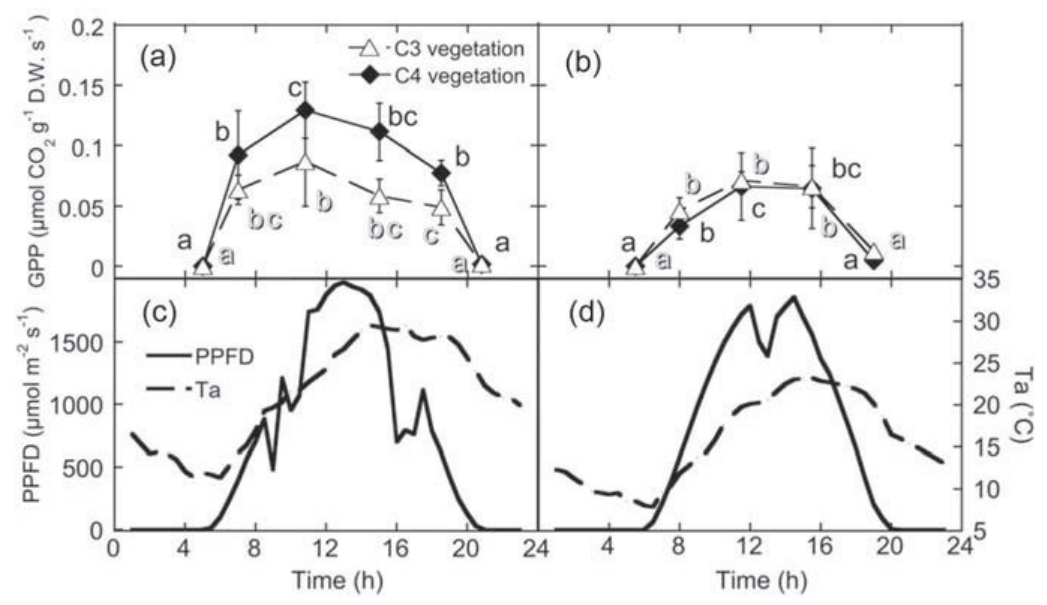

Fig. 2. Diurnal variations in GPP in $C_{3}$ and $C_{4}$ vegetation on 11 July (a) and 22 August (b), and photosynthetic photon flux density (PPFD) and air temperature (Ta) on 11 July (c) and 22 August (d) 2003. Time of day is local Mongolian Daylight Saving Time. Bars represent standard deviation $\left(n=4\right.$ for $\mathrm{C}_{3}$ vegetation, $n=3$ for $\mathrm{C}_{4}$ vegetation). Different letters indicate significant difference by Tukey's HSD test $(p<0.05)$.

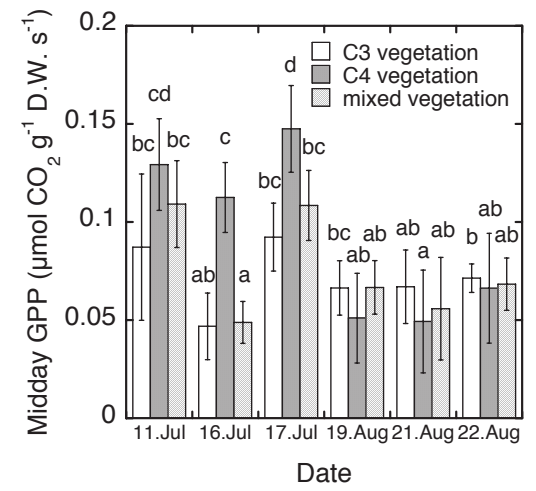

Fig. 3. Midday GPP (dry-weight basis) of $\mathrm{C}_{3}$ vegetation, $\mathrm{C}_{4}$ vegetation, and mixed $\mathrm{C}_{3}-\mathrm{C}_{4}$ vegetation. Midday GPP was measured in the NGA in July and August of the first year after exclosure establishment (2003). Bars represent standard deviation $(n=4$ for $\mathrm{C}_{3}$ vegetation, $n=3$ for $\mathrm{C}_{4}$ vegetation, $n=10$ for mixed $\mathrm{C}_{3}-\mathrm{C}_{4}$ vegetation). Different letters indicate significant difference by Tukey's HSD test $(p<$ $0.05)$.

\subsection{GPP in $\mathrm{C}_{3}, \mathrm{C}_{4}$, and $\mathrm{C}_{3}-\mathrm{C}_{4}$ mixed vegetation} We examined the midday dry-weight-based GPP in $\mathrm{C}_{3}$ vegetation, $\mathrm{C}_{4}$ vegetation, and mixed $\mathrm{C}_{3}-\mathrm{C}_{4}$ vegetation in the NGA in July and August 2003 (see Fig. 3). Midday GPP tended to be higher in July than in August. On 16 July, midday GPP was lower in $\mathrm{C}_{3}$ vegetation and mixed $\mathrm{C}_{3}-\mathrm{C}_{4}$ vegetation, but there was little temporal change in GPP of $\mathrm{C}_{4}$ vegetation throughout July. In July, midday GPP was higher in $\mathrm{C}_{4}$ vegetation than in $\mathrm{C}_{3}$ vegetation or mixed $\mathrm{C}_{3}-\mathrm{C}_{4}$ vegetation. In August, there were no significant differences in midday GPP between measurement dates or between vegetation types.

We examined the daily mean volumetric SWC and $T a$ on the PPFD measurement dates in 2003 and 2006 (see Table 2). In 2003, SWC was variable and $T a$ was higher in July than in August. The lowest SWCs (5\%-6\%) were found on 11 and 16 July 2003, before which no rain had fallen. Rainfall on the night of 16 July $(18 \mathrm{~mm})$ raised the SWC from $<5.5 \%$ to $>15 \%$, and rainfall $(22 \mathrm{~mm})$ on 20 August doubled the SWC of 21 August compared with 19 August in both the GA and NGA. The SWC then decreased to $13.6 \%$ in the GA and to $12.8 \%$ in the NGA by 23 August.

In July 2003, daily mean $T a$ varied within a narrow range of 21 to $23^{\circ} \mathrm{C}$. However, in August 2003, Ta was lower the day after rainfall. SWC and $T a$ in late July 2006 were within the range of values observed in early July and August 2003. Thus, the mean midday GPP in the GA and NGA was measured under comparable SWC and temperature conditions in both years.

\subsection{Contributions of $\mathrm{C}_{3}$ and $\mathrm{C}_{4}$ photosynthesis to mixed-vegetation GPP}

To verify the accuracy of the $\mathrm{C}_{3}$ and $\mathrm{C}_{4}$ plant GPPs estimated by Equation (1) and (2), we plotted midday land-area-based GPP measured in mixed $\mathrm{C}_{3}-\mathrm{C}_{4}$ 
Table 2. Daily means of soil water content (SWC) and air temperature $(T a)$ in the GA and NGA. Observations were taken from the meteorological towers on the PPFD measurement dates in 2003 and 2006.

\begin{tabular}{|c|c|c|c|c|c|c|c|c|c|}
\hline & \multicolumn{7}{|l|}{2003} & \multirow{2}{*}{$\frac{2006}{30 \mathrm{Jul}}$} \\
\hline & & $11 \mathrm{Jul}$ & 16 Jul & $17 \mathrm{Jul}$ & 19 Aug & $21 \mathrm{Aug}$ & 22 Aug & 23 Aug & \\
\hline \multirow[t]{2}{*}{ SWC (\%) } & GA & 5.9 & 5.5 & 16.1 & 9.1 & 17.8 & 15.7 & 13.6 & 8.9 \\
\hline & NGA & 5.6 & 5.2 & 15.2 & 8.6 & 16.8 & 14.8 & 12.8 & 8.4 \\
\hline \multirow[t]{2}{*}{$\operatorname{Ta}\left({ }^{\circ} \mathrm{C}\right)$} & GA & 21.0 & 22.9 & 22.1 & 15.4 & 13.7 & 15.6 & 15.9 & 18.0 \\
\hline & NGA & 21.0 & 23.0 & 22.1 & 15.2 & 13.6 & 15.5 & 15.8 & 17.9 \\
\hline
\end{tabular}

vegetation against the midday GPP of mixed $\mathrm{C}_{3}-\mathrm{C}_{4}$ vegetation calculated from the measured GPPs of $\mathrm{C}_{3}$ and $\mathrm{C}_{4}$ vegetation in the NGA in 2003 and the AGB ratio of $\mathrm{C}_{3}$ and $\mathrm{C}_{4}$ plants measured in 2003 (see Fig. 4). The data plot shows a linear correlation between the measured and calculated GPP $(y=0.79 x+1.69, r=$ $0.98, p<0.001)$.

We plotted the contributions of $\mathrm{C}_{3}$ and $\mathrm{C}_{4}$ photosynthesis to midday land-area-based GPP measured in the mixed $\mathrm{C}_{3}-\mathrm{C}_{4}$ vegetation in the GA and NGA in 2003 and 2006 (refer to Fig. 5). There was no significant difference in measured midday GPP between the two areas in either year. The contributions of both $\mathrm{C}_{3}$ and $\mathrm{C}_{4}$ photosynthesis did not differ between the GA and NGA in 2003, but contribution of $\mathrm{C}_{3}$ was significantly greater and of $\mathrm{C}_{4}$ was significantly smaller in the NGA than in the GA in $2006(p<0.05)$.

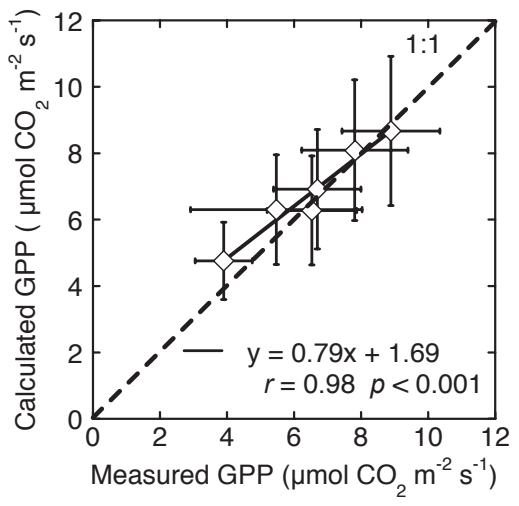

Fig. 4. Relationship between measured and calculated midday GPP on a land-area basis in mixed $\mathrm{C}_{3}-\mathrm{C}_{4}$ vegetation. The calculated GPPs were obtained from midday GPPs measured in exclusively $\mathrm{C}_{4}$ or $\mathrm{C}_{3}$ vegetation in the NGA in 2003 and from the aboveground biomass ratios of $\mathrm{C}_{3}$ and $\mathrm{C}_{4}$ plants measured in the GA and NGA in 2003. Horizontal bars show means and standard deviations (SDs) of the measured midday GPP $(n=10)$, and vertical bars show calculated midday GPP $(n=12)$.
We examined the relationship between AGB and land-area-based midday GPP measured in mixed $\mathrm{C}_{3}-\mathrm{C}_{4}$ vegetation in the GA and NGA on 30 July 2006 (refer

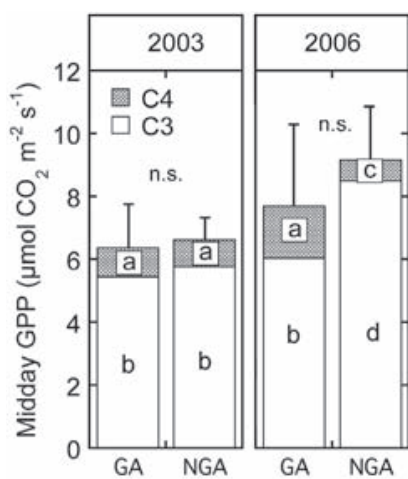

Fig. 5. Contributions of $\mathrm{C}_{3}$ and $\mathrm{C}_{4}$ photosynthesis to midday GPP estimated in mixed $\mathrm{C}_{3}-\mathrm{C}_{4}$ vegetation in the GA and NGA on 23 August 2003 and 30 July 2006. Contributions were calculated from the results in Fig. 3 and Equation (2). Bars represent standard deviations. Statistical comparisons were made by Tukey's HSD test $(p<0.05)$.

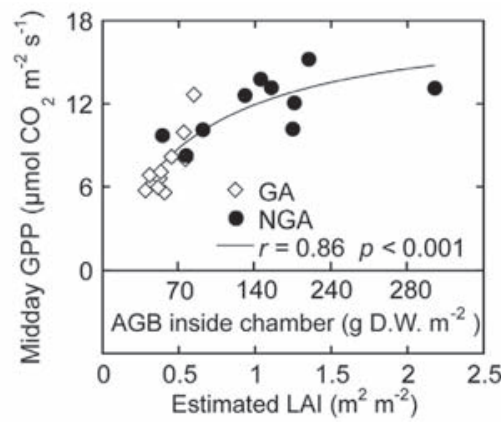

Fig. 6. Relationship between estimated LAI inside the chamber and midday GPP measured on a land-area basis in mixed $\mathrm{C}_{3}-\mathrm{C}_{4}$ vegetation in the GA and NGA on 30 July 2006. Results represent data obtained from 10 chambers used for flux measurement in both the GA and NGA. 
Table 3. Multiple regression for $\mathrm{AGB}$ and midday GPP ( $\mu \mathrm{mol} \mathrm{CO}_{2} \mathrm{~g}^{-1}$ D.W.

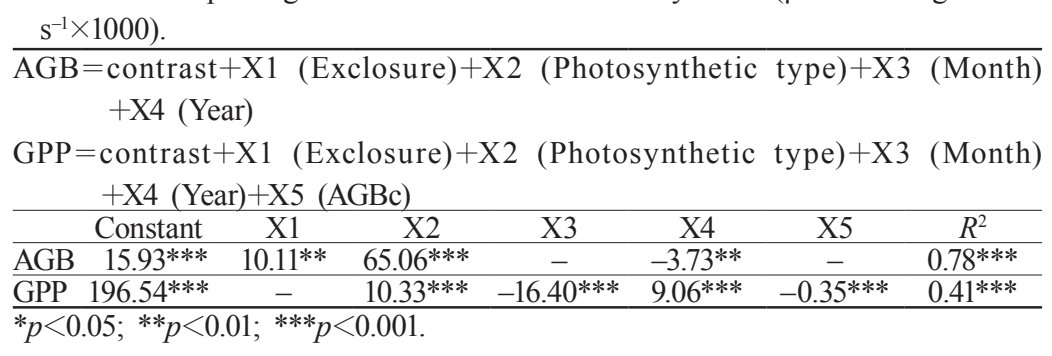

to Fig. 6). The relationship between Midday GPP and AGB was described by the GPP-LAI regression model, with significant correlation coefficients for all parameters $(a=18.55, t$-value $=8.96, p<0.001 ; b=0.55$, $t$-value $=3.82, p<0.005 ; r=0.86, p<0.001)$. Midday GPP increased with a saturation curve with increasing AGB. The stepwise multiple analysis showed that significant variables for predicting midday GPP variations were photosynthetic type, month, year, and AGB, but not exclosure (see Table 3).

\section{Discussion}

\subsection{Temporal variation in $\mathrm{AGB}$ and GPP of $\mathrm{C}_{3}$ and $\mathrm{C}_{4}$ plants in summer}

In general, $\mathrm{C}_{4}$ plants have higher photosynthetic activity and a larger tolerance of drought stress than $\mathrm{C}_{3}$ plants, but their photosynthetic systems need higher temperatures. Daytime GPP of $\mathrm{C}_{4}$ vegetation was greater than that of $\mathrm{C}_{3}$ vegetation on 11 July, but there was no clear difference on 22 August (refer to Fig. 2). The reduced GPP of $\mathrm{C}_{4}$ vegetation on 22 August may have been caused by a decrease in temperature. Larcher (2003) reported that $\mathrm{C}_{4}$ plants may become stressed at temperatures below $7^{\circ} \mathrm{C}$. The daily minimum temperature declined by nearly $7^{\circ} \mathrm{C}$ from July to August (see Fig. 2), and damage to the photosynthetic mechanisms of the $\mathrm{C}_{4}$ plants or senescence of these plants during August may have occurred. In Mongolia, $\mathrm{C}_{4}$ plants require average monthly temperatures of $>20^{\circ} \mathrm{C}$ for active growth (Liang et al., 2002). On the KBU steppe, monthly air temperatures exceed $20^{\circ} \mathrm{C}$ only in July (Kawada et al., 2007). This northern high-altitude climate would therefore seem to disadvantage $\mathrm{C}_{4}$ plants. However, although low temperatures restricted the GPP of $\mathrm{C}_{4}$ plants, arid conditions, when they occurred, favored $\mathrm{C}_{4}$ plants over $\mathrm{C}_{3}$ plants (see Table 2, Fig. 3). In $\mathrm{KBU}$, annual precipitation did not exceed $260 \mathrm{~mm}$ during our measurement term, and because a calcic layer is present, it is difficult for the plants there to use groundwater (Li et al., 2005; Asano et al., 2007). High water stress and temperature variability are likely to cause temporal changes in the relative advantages of $\mathrm{C}_{3}$ and $\mathrm{C}_{4}$ plants in terms of GPP. Midday GPP in the mixed $C_{3}-C_{4}$ vegetation ranged between $C_{3}$ and $\mathrm{C}_{4}$ GPP values over the measurement term (refer to Fig. 3). Midday GPP estimated from $C_{3}$ and $C_{4} A G B$ was well correlated with measured midday GPP (refer to Fig. 4), indicating that GPP in the mixed $C_{3}-C_{4}$ vegetation can be described by the ratio of $\mathrm{C}_{3} \mathrm{AGB}$ to $\mathrm{C}_{4} \mathrm{AGB}$.

\subsection{Effect of grazing on AGB}

In general, high grazing pressure decreases AGB in temperate grasslands (Hayashi, 2003; Zhao et al., 2005) because of a direct effect of feeding on biomass and an indirect effect of nutrient loss on productivity. Zhao et al. (2005) reported that the AGB of grassland in Inner Mongolia declined the year after heavy grazing. The major grazing impact is selective feeding and trampling by domestic animals, influencing species composition (Schütz et al., 2003, Tessier et al., 2003, Sasaki et al., 2007). However, the KBU steppe showed no significant changes in $\mathrm{AGB}$ or the ratio of $\mathrm{C}_{4} \mathrm{AGB}$ to total $\mathrm{AGB}$ in the first year after exclosure, implying that our study area had been lightly (not heavily) grazed. However, even light grazing can have a cumulative influence on AGB and species composition. In fact, this relatively light grazing resulted in significant changes in the $\mathrm{AGB}$ and the ratio of $\mathrm{C}_{4} \mathrm{AGB}$ to total AGB after the second year; light grazing, therefore, appears to have a cumulative influence on vegetation structure and the carbon cycle in the KBU steppe.

The vegetation of the KBU steppe included three major $\mathrm{C}_{4}$ plants: S. collina, K. scoparia, and C. squarrosa. It is well known that $S$. collina and $K$. scoparia prefer disturbed areas (Commissione Redactorum Florae Intramongolicae, 1990). An exclosure study in Inner Mongolia demonstrated that the AGB of C. squarrosa was larger in a grazed plot than in a nongrazed plot 
(Chen et al., 2005). These studies may explain the increased ratio of $\mathrm{C}_{4} \mathrm{AGB}$ to total $\mathrm{AGB}$ in the GA in the KBU steppe.

Stepwise multiple regression suggested no monthly variation in AGB in midsummer (July and August), indicating that $\mathrm{AGB}$ can be compared with annual variation of AGB in midsummer (see Table 3). Figure 1 shows decreasing total AGB between 2003 and 2006 in the GA with the same ratio of $\mathrm{C}_{4} \mathrm{AGB}$ in midsummer. These results suggest increasing grazing impacts on both $\mathrm{C}_{3}$ and $\mathrm{C}_{4}$ AGB. Further studies of both long-term vegetation recovery in an NGA and of interannual variations in grazing pressure in a GA are needed.

\subsection{Effect of grazing on GPP}

The midday GPP of our study grassland increased with increasing AGB (refer to Fig. 6). Moreover, the typical hot dry conditions of midsummer in Mongolia are more suited to $\mathrm{C}_{4}$ photosynthesis. Our finding that in July 2003 there was no difference in the midday GPP of $\mathrm{C}_{4}$ vegetation before and after rainfall indicates that the midday GPP of $\mathrm{C}_{4}$ vegetation depended on the ratio of $\mathrm{C}_{4}$ AGB to total AGB (see Fig. 3). Therefore, excluding the effects of midsummer, midday GPP will vary positively with total $A G B$ and with the $\mathrm{C}_{4} \mathrm{AGB}$ to total AGB ratio.

In the first year (2003), a lack of differences in total $\mathrm{AGB}$ and in the ratio of $\mathrm{C}_{4} \mathrm{AGB}$ to total $\mathrm{AGB}$ between the GA and NGA led to similar midday GPPs in the two areas. In the fourth year (2006), the increased AGB in the NGA should have resulted in an increased midday GPP, but the decreased AGB of $\mathrm{C}_{4}$ plants (which have high photosynthetic performance) and self-shading by the increased AGB may have offset any increase in midday GPP in the NGA (refer to Figs. 1, 5, 6). The offset effects apparently result in no significant difference in midday GPP between the GA and NGA in 2006.

Our result shows one of the offset effects is decreased $\mathrm{C}_{4}$ plants in NGA. In the NGA, larger $\mathrm{AGB}$ of $\mathrm{C}_{3}$ plants statistically increased GPP of $\mathrm{C}_{3}$ plants than in the GA; however, decreased $\mathrm{AGB}$ of $\mathrm{C}_{4}$ plants statistically decreased GPP of $\mathrm{C}_{4}$ plants in 2006. In the GA, on the contrary, $\mathrm{C}_{4}$ plants contributed $15 \%$ to total AGB and high photosynthesis activity of $\mathrm{C}_{4}$ plants contributed more than 27\% to total GPP in 2006 (Fig. 5). These results suggest overgrazing and global warming might cause more large contribution of $\mathrm{C} 4$ plants to AGB and GPP in Mongolian steppe.
Photosynthetic activities, expressed as the slope of the non-linear relation between midday GPP and AGB (refer to Fig. 6). Generally, grazing causes regrowth of plants for cover cutting damage and loss of photosynthetic organs (Bovolenta et al., 2008). However, stepwise multiple regression suggested that nongrazing had not caused changing of GPP per AGB, indicating that regrowth had little affected GPP in NGA (Table 3). Especially, self-shading may be saturated GPP against AGB. Byrne et al. (2005) used the Michaelis-Menten kinetics to describe the response of GPP to the leaf area index (LAI), and showed that the ratio of the GPP increment decreased when the LAI exceeded $2 \mathrm{~m}^{2} \mathrm{~m}^{-2}$. GPP saturation against the LAI was discussed as tiller density of grass. In our study, the estimated LAI inside the chamber reached $2.2 \mathrm{~m}^{2} \mathrm{~m}^{-2}$ (Fig. 6), despite plant height being $<32 \mathrm{~cm}$ (Kawada et al., 2007). This suggests that the removal of grazing caused a high plant shoot density. Moreover, the result of the GPP-LAI regression model shows the slope of saturation curve is sharper than other temperate grasslands (Byrne at al., 2005). This result might be caused by shades of high density standing litter; therefore forward studies need to evaluate how standing litter affect gross primary productivity. It is interesting that shading may suppress GPP even in a Mongolian semi-arid grassland with AGB lower than those of other semi-arid grasslands (Flanagan et al., 2002). Our results indicate that a positive control of AGB in the exclosure cannot be sustained over the long term.

\section{Conclusion}

We showed the effects of 5 years of exclosure on AGB, vegetation composition, and GPP in midsummer on a semi-arid Mongolian steppe. Exclosure altered AGB and vegetation composition. In the exclosure, total AGB increased and the ratio of $\mathrm{C}_{4}$ species biomass to total AGB decreased between the start and end of our study; however, midday GPP in both grazed and ungrazed areas was similar in the first and fourth years following exclosure. Partitioning of midday GPP according to $\mathrm{C}_{3}$ and $\mathrm{C}_{4}$ photosynthesis indicated that exclosure treatment can exert a small influence on GPP - at least on the midday GPP in midsummer - because of a low ratio of $\mathrm{C}_{4} \mathrm{AGB}$ to total AGB and decreasing midday GPP per AGB.

In the $\mathrm{KBU}$ steppe in midsummer, the $\mathrm{C}_{4}$ species biomass occupied $14 \%$ to $15 \%$ of the total AGB in 
the grazed area, and air temperature was high enough to increase $\mathrm{C}_{4}$ plant photosynthesis, contributing greatly to the overall GPP. Inside the exclosure, a reduction in $\mathrm{C}_{4}$ species biomass caused a decrease in midsummer GPP. Because our study was carried out only in the KBU steppe, the results may not apply to other types of Mongolian steppe (e.g., mountain forest steppe or desert steppe). However, because most of the Mongolian steppe is composed of mixed $\mathrm{C}_{3}-\mathrm{C}_{4}$ vegetation (Pyankov et al., 2000), our results suggest that the contribution of $\mathrm{C}_{4}$ plant biomass to the plant community is an important element controlling GPP in the Mongolian steppe.

Most exclusion studies have focused on AGB and species composition in order to clarify recovery processes or plant growth patterns in different soil properties of vegetation. under different environmental conditions (Tessier et al., 2003, Su et al., 2005, Pei et al., 2008). However, little is known of the effects of exclosure on interannual variation in community composition and GPP, despite GPP being one of the most important functions of vegetation when management options for livestock are considered. Therefore, our study will provide useful information for more effective management of the productivity of a steppe under grazing stress.

\section{Acknowledgements}

We thank Dr. G. Davaa, Mr. D. Oyunbaatar, and others at the Institute of Meteorology and Hydrology of Mongolia. The authors also express their appreciation to Y. Sawaguchi of the Japan Science and Technology Agency (JST) for managing various administrative issues of RAISE project. This study has been supported, in part, by JST through grant under the Core Research for Evolutional Science and Technology (CREST) program funded for the RAISE (Rangelands Atmosphere-Hydrosphere-Biosphere Interaction Study Experiment in Northeastern Asia) project. Partial support came also from the Global Environment Research Fund of the Ministry of Environment of Japan, from the Grant-In-Aid for Science, and from the University of Tsukuba Research Project A.

\section{References}

Asano, M., Tamura, K., Kiyokazu, and K., Higashi., 2007: Morphological and physico-chemical characteristics of soils in a steppe region of the Kherlen River basin, Mongolia. J. Hydrol., 333, 100-108.
Bovolenta, S., Spanghero, M., Dovier, S., Orlandi, D., and Clementel, F., 2008: Chemical composition and net energy content of alpine pasture species during the grazing season. Anim. Feed Sci. Tech., 146, 178-191.

Byrne, K. A., Kiely, and G., Leahy, P., 2005: $\mathrm{CO}_{2}$ fluxes in adjacent new and permanent temperate grasslands. Agric. For. Meteorol., 135, 82-92.

Chen, S. P., Bai, Y. F., Lin, G. H., Liang, Y., and Han, X. G., 2005: Effects of grazing on photosynthetic characteristics of major steppe species in the Xilin River Basin, Inner Mongolia, China. Photosynthesis, 43, 559-565.

Commissione Redactorum Florae Intramongolicae, 1990: FLORA INTRAMONGOLICA EDITIO SECUNDA Tomus 2. Intramongolicae Popularis, Huhhot, 759pp.

Fernandez-Gimenez, M. E., and Allen-Diaz, B., 1999: Testing a non-equilibrium model of rangeland vegetation dynamics in Mongolia. J. Appl. Ecol., 36, 871-885.

Flanagan, L., Wever, L. A., and Carlson, P. J., 2002: Seasonal and interannual variation in carbon dioxide exchange and carbon balance in a northern temperate grassland. Glob. Change Biol., 8, 599-615.

Hayashi, I., 2003: Plant ecology: principles and applications., Kokinshoin, Tokyo, 227pp.

Jigmed, G., 2006: The current situation of grassland resources in Mongolia. Bull. Fac. Agric. Niigata Univ., 58, 133-136.

Kawada, K., Urano, T., Lee, G., Mariko, S., and Nakamura, T., 2007: Structure of a plant community and variance of biomass under over-grazed environment in Kherlen Bayan-Ulaan, Mongolia. J. Arid Land Stud., 17, 1-10.

Larcher, W., 2003: Physiological plant ecology: ecophysiology and stress physiology of functional groups., Springer, 513pp.

LeCain, D. R., Morgan, J. A., Schuman, G. E., Reeder., J. D., and Hart, R. H., 2002: Carbon exchange and species composition of grazed pastures and exclosures in the shortgrass steppe of Colorado. Agric. Ecosyst. Environ., 93, 421-435.

Li, S. G., Lai, C., T., Yokoyama, T., and Oikawa, T., 2003: Carbon dioxide and water vapor exchange over a Miscanthus-type grassland: Effets of development of the canopy. Ecol. Res., 18, 661-675.

Li, S. G., Asanuma, J., Eugster, W., Kotani, A., Liu, J. J., Urano, T., Oikawa, T., Davaa, G., Oyunbaatar, D., 
and Sugita, M., 2005: Net ecosystem carbon dioxide exchange over grazed steppe in central Mongolia. Glob. Change Biol., 11, 1-15.

Liang, C., Michalk, D. L., and Millar, G. D., 2002: The ecology and growth patterns of Cleistogenes species in degraded grasslands of eastern Inner Mongolia, China. J. Appl. Ecol., 39, 584-594.

Nachinshonhor, U. G., Tserendash, S., Jargalsaikhan, L., Thooj, S., Tsendeekhuu, T., Dugarjav, C., and Hirose, T., 2000: Effects of climate and nomadic activities on the structure of grassland vegetation in Mongolia: Experimental design and the first-year survey. Rep. Grant-in-Aid for Scientific Research (B)(2)., 45-55.

Onda, Y., Kato, H., Tanaka, Y., Tsujimura, M., Davaa, G., and Oyunbaatar, D., 2007: Analysis of runoff generation and soil erosion processes by using environmental radionuclides in semiarid areas of Mongolia. J. Hydrol., 333, 124-132.

Pei, S., Fu, Hua., and Wan, C., 2008: Changes in soil properties and vegetation following exclosure and grazing in degraded Alxa desert steppe of Inner Mongolia, China. Agr. Ecosyst. Environ., 124, 33-39.

Pyankov, V. I., Gunin, P. D., Tsoog, S., and Black, C. C., 2000: $\mathrm{C}_{4}$ plants in the vegetation of Mongolia: Their natural occurrence and geographical distribution in relation to climate. Oecologia, 123, 15-31.

Sasaki T., Okayasu, T., Shirato, T., Undarmaa J., and Takeuchi K., 2007. Quantifying the resilience of plant communities under different grazing intensities in a degraded shrubland: A case study in Mandalgobi, Mongolia. Grassl. Sci, 53, 192-195.
Schütz, M., Risch, A. C., Leuzinger, E., Krüsi, B.O., and Achermann, G., 2003. Impact of herbivory by red deer (Cervus elaphus L.) on patterns and processes in subalpine grasslands in the Swiss National Park. For. Ecol. Manag., 181, 177-188.

Su, Y. Z., Li, Y. L., Cui, J. Y., Zhao, W. Z., 2005: Influences of continuous grazing and livestock exclusion on soil properties in a degraded sandy grassland, Inner Mongolia, northern China. Catena, 59, 267-278.

Sugita, M., Asanuma, J., Tsujimura, M., Mariko, S., Lu, M., Kimura, F., Azzaya, D., and Adyasuren, Ts., 2007: RAISE Database, Terr. Environ. Res. Center. Univ. Tsukuba.

Tessier, M., Vivier, J. P., Ouin, A., Gloaguen, J. C., and Lefeuvre, J. C., 2003. Vegetation dynamics and plant species interactions under grazed and ungrazed conditions in a western European salt marsh. Acta Oecolog., 24, 103-111.

Urano, T., 2006: Contribution of $\mathrm{C}_{3}$ and $\mathrm{C}_{4}$ plants for gross production in Mongolian semi-arid stepp. Bull. Terr. Env. Res. Cent. Univ. Tsukuba. 7 Suppl., 2, 9-10.

Zhang, M. A., Borjigin, E., and Zhang, H., 2007: Mongolian nomadic culture and ecological culture: On the cological reconstruction in the agro-pastoral mosaic zone in Northern China. Ecol. Econ., 62, 19-26.

Zhao, H. L., Zhao, X. Y., Zhou, R. L., Zhang, T. H., and Drake, S., 2005: Desertification processes due to heavy grazing in sandy rangeland, Inner Mongolia. J. Arid Env., 62, 309-319. 